\title{
BIBLIOGRAFIA GEOGRÁFICA DE PORTUGAL CONTINENTAL
}

1979

\section{DOCUMENTAÇÃO}

BIBLIOGRAFIA

1. AMARAL, ILÍDIo DO - A "Escola Geográfica de Lisboa», e a sua contribuição para o conhecimento geográfico das regióes tropicais, Centro de Estudos Geográficos, Lisboa, 1979, 87 p., pol. (Estudos de Geografia das Regiões Tropicais - 1).

História das contribuições da "Escola Geográfica de Lisboa» para o conhecimento das regiões tropicais, desde o início do século. Bibliografia anotada (213 títulos).

2. Desenvolvimento regional em Portugal, 1970-1979 - Bibliografia sinalética. Lisboa, Junta Nacional de Investigação Cientifica e Teconológica, C. I. U. R. 1979,169

Bibliografia especializada e abrangendo 829 referências.

3. Elementos para uma bibliografia portuguesa sobre política social, 1970 -1979. Lisboa, Secretaria de Estado do Planeamento - Gipso, 1979, 155 p.

Abrange (em 1630 títulos) os aspectos da habitação, agricultura, ambiente, saúde, segurança social, trabatho e emigração.

4. ROSEIRA, Maria JOÃO QUDIROZ - "Bibliografia Geográfica de Portugal Continental - 1978». Finisterra, Lisbon, XIV, 28, 1979, p. 269-302

São enumeradas e anotadas 214 espécies.

CARTOGRAFIA

Atlas

5. Atlas do Ambiente. Escala 1:1000000. Lisbon, Comissão Nacional do Ambiente.

Folhas editadas em 1979

- Carta dã clistribuição de alfarrobeira e amendoeira;

- $\gg 》$ de figueira e medronheiro;

- $\gg "$ da videira;

- " " de oliveira e zambujeiro. 
Mapas

6. Barra e Porto de Setúbal. Escala 1:25:000.

Lisboa, Instituto Hidográfico, 1979.

7. Carta Agricola e Florestal de Portugal. Escala: 1:25000. Lisboa, Direcção-Geral de Hidráulica e Engenharia Agrícola - Ministério da Agricultura e Pescas.

Folhas publicadas em 1979:

90 (Franco), 91 (Frechedo), 104 (Vilas Boas), 105 (Vila Flor), 117 (Carrazeda de Anciâes), 118 (Castelo), 129 (Seixo de Anciães), 130 (Torre de Mancorvo), 199 (Tondela), 200 (Nelas), 208 (Anadia), 209 (Mortágua), 210 (Santa Comba Dão), 211 (Ervedal da Beira), 217 (Tooha), 218 (Cantanhede) e 219 (Meallhada).

8. Carta Corográfica de Portugal. Escala 1:50000. Lisboa, Instituto Geográfico e Cadastral.

Folhas editadas em 1979:

15-C (Pinhel), 21-A (Sabugal), 28-C (Gavião), 40-C (Viana do Alentejo), 41-A (Monsaraz), 43-C (Beja), 44-A (Amareleja).

9. Gonçalves, Francisco; Zbyszewsin, G.; Caryalhosa, A. BarrosCarta Geológica de Portugal. Notícia explicativa da Folha 27-D (Abrantes). Lisboa, Serviços Geológioos de Portugal, 1979, 75 p.

10. Martins, J. Ávila; Ribeiro, Maria Luísa-Carta Geológica de Portugal. Noticia explicativa da Folha 2-C (Tourém). Lisboa, Serviços Geológimos de Portugal, 1979, 29 p., bibliog.

11. ZBYSZEWSTI, G.; FERREIRA, O. DA VEIGA - Carta Geológica de Portu\&gal. Noticia explicativa da Folha 31-B (Chauto). Lisboa, Serviços Geológicos de Portugal, 1979, $27 \mathrm{p}$.

12. ZbYszewsik, G.; Ferreira, O. Da Veiga; Carvalhosa, A. BarrosCarta Geológica de Portugal. Noticia explicativa da Folha 35-B (Mora). Lisboa, Serviços Geológicos de Portugal, 1979, 33 p.

13. Carta Militar de Portugal. Escala 1:25000. Lisboa, Serviço Cartográfico do Exército.

Folhas editadas (2. edição) em 1979:

85 (Guimarães), 112 (Penafíel), 135 (Castelo de Par̂va), 144 (Canêdo - Feira), 154 (S. João da Madeira), 227-B (Murtinheira-Figueira da Foz), 238-A (Vais - Figueira da Foz), 582 (Vaqueiros), 584 (Aljezur), 585 (Monchique), 586 (Amorosa-Silves), 587 (S. Bartolomeul de Messines), 592 (Bordeira-Aljezur), 594 (Mexilhoeira Grande-Portimão), 595 (Silves), 604 (Lagoa), 606 Loulé).
14. Carta de Portugal. Escala 1:100 000. Lisboa, Instituto Geográfico e Cadastral.

Folhas editadas em 1979:

29 (Marvão) e 41 (Mourão)

15. Porto de Sines. Escala 1:15 000. Lisboa, Instituto Hidrográfico, 1979.

16. Porto de Lisboa. Escala 1:25000. Lisboa, Instituto Hidrograficto, 1979.

17. Silva Climática de Portugal. Escala 1:500000. Oeiras, Estação Agronómica, 1979. 3 cores de base e 15 de mancha, $1,45 \mathrm{~m} \times 0,75 \mathrm{~m}$ de dimensão, sem curvas de nível.

Presenças actuais ou retrospectivas das espécies lenhosas indicadoras.

ESTATISTICA

18. Estatisticas Agricolas (1978). Lisboa, Instituto Nacional de Estatística, $1979,217 \mathrm{p}$.

19. Estatisticas das Contribuições e Impostos (1978). Lisboa, Instituto Nacional de Estatística, 1979, 125 p.

20. Estatísticas de Educação (1978). Lisboa, Instituto Nacional de Estatística, 1979,220 p.

21. Estatisticas da Energia (1977 e 1978). Lisboa, Instituto Nacional de Estatística, 1978,96 p. e 1979,100 p.

22. Estatisticas das Finanças Públicas (1977). Lisboa, Instituto Nacional de Estatística, 1979, $71 \mathrm{p}$.

23. Estatísticas Industriais (1977), vol. II: Induistrias Transformadoras. Lisboa, Instituto Nacional de Estatística, 1979, 763 p.

24. Estatisticas da Justiça (1978). Lisboa, Instituto Nacional de Estatística, $1979,157 \mathrm{p}$.

25. Estatisticas Monetírias e Financeiras (1978). Continente e Regiões Autónomas dos Açores e Madeira. Lisboa, Instituto Nacional de Estatística, $1979,107 \mathrm{p}$.

26. Estatisticas da Pesca (1978). Lisboa, Instituto Nacional de Estatística, 1979,56 p.

27. Estatísticas da Satide (1978), vol. I: Pessoal, Estabelecimentos de Saúde, Morbilidade e Mortalidade Fetal. Lisboa, Instituto Nacional de Estatística, $1979,83 \mathrm{p}$.

28. Estatisticas do Turismo (1978). Lisboa, Instituto Nacional de Estatística, $1979,395 \mathrm{p}$. 
29. Inquérito Permanente ao Emprego. Continente, 1974/77. Série retrospectiva. Lisboa, Instituto Nacional de Estatística, 1979, 109 p.

Resultados sobre emprego, desemprego e outras características da população activa.

30. Inquérito ao Transporte Rodoviário de Mercadorias. Continente, 1975. Lisboa, Instituto Nacional de Estatística, 1979, 166 p.

Os dados são fornecidos a nível de concelho e incluem quadros com n. ${ }^{\circ}$ de veículos, pessoal, despesas, percursos, etc.

31. Recenseamento à Distribuição e Serviços. Portugal: Distritos de Aveiro, Coimbra, Faro, Lisboa, Porto e Setibal, 1977-1979. Lisboa, Instituto Nacional de Estatística, 1979, 476 p.

32. Recenseamento eleitoral $78 / 79$ e actualização de 1979. Lisboa, Ministério da Administração Interna - STAPE, 1979, $151 \mathrm{p}$.

Contém os resultados definitivos, por freguesias e concelho. Compreende também os resultados das Regióes Autónomas de Macau e dos postos consulares.

\section{PARTE HISTÓRICA}

GERAL

33. ANaCleto, Joño Josê; QUaResma, Još́ ALBERTo - «Portimão em 1810. Esboço de análise sócio-económica». História e Sociedade, Lisboa, 4-5, 1979 , p. $41-51$.

Elementos sucintos sobre Portimão, Alvor e Montes, no início do século XIX (população, fogos, prédios e sua respectiva utilização, arruamentos, estrutura da propriedade, foros, etc.).

34. ANdrade, ANTónio Alberto BanHa DE - "Conspecto sócio-económico de uma vila alentejana da Renascençà.Anais da Acadęmia Portuguesa de História, Lisboa, II série, 25, 1979, p. 159-274.

Entre outrós, elementos sobre o regime de prop̣riedade, produções, receitas e impostos de Montemor-o-Novo, no período 1415-1580.

35. ARaújo, Agostinfio - «O desenvolvimento urbano da Póvon de Varzim na segunda metade do século xvir. Boletim Cultural da Póvoa de Varzim. Póvoa de Varzim, XVIII, 1, 1979, p. 105-154.

Continuação de artigo anterior (na BGP de 1978 é o n. $45-F i$ nisterra, XIV-28). A pêndice documental.

36. ARAúJo, Ilídio Alves $\mathrm{DE}$ - "A revolução do milho vista duma aldeia do Minho Serrano». História e Ideias. Porto, 3-4, 1979, p. 19-34.

Reedição de um trabalho elaborado em 1956 e em que é focada a história da ocupação agrícola, os modos de vida e as consequências económicas e sociais resultantes da introdução do milho numa pequena comunidade rural minhota (Pedroso).
37. BENIS, MARIA IOANNIS - "A emigração de 1856 a 1875 vista de Viana do Castelo». Revista de História Económica e Social, Lisboa, 3, 1979, p. $85-100$.

Com base nos artigos publicados nos dois periódicos locais, análise, næ perspectiva regional, do problema da emigração.

38. Cabral, MANued Villaverde-Portugal na alvorada do século $X X$. Forças sociais, poder politico e crescimento económico de 1980 a 1914. Lisboa, A Regra do Jogo, 1979, XIX + 473 p.

Evolução económica e social de Portugal desde 1890 ao inicio da 1." Grande Guerra.

39. CARREIRa, ANTÓNIO - Tráfico português de escravos. Lisboa, Junta de Investigações Científicas do Ultramar - Centro de Estudos de Antropologia Cultural, 1979, 125 p. il., quad.

A partir de relações de navios negreiros (actuando na closta Oriental de Africa, no período 1786-1832), elementos sobre mercadorias, pre९os, itinerários, escravos, etc.

40. Castelo-Branco, Fernando - "Vinho e vinhas em Lisboa". Lisboa (Revista Municipal). Lisboa, XL, 1, 1979, p. 18-23, il.

Breves elementos sobre a distribuição da vinha no perímetro da cidade, desde a Idade Média até ao fim do século XIX e sobre a sua importância no labastecimento de vinho a Lisboa.

41. Conlmo, VIRGinia - «Precos do azeite em Lisboa: 1626-1733. Tentativa de compreensão analítico-sintétican. Revista de História Económica e Social. Lisboa, 4, 1979, p. 15-39, bibl.

Análise da relação entre os preços do azeite e a evolução económica do país.

42. CONSTÂncio, SOLANo - Portugal e o Mundo nos $1.0 s$ decénios do século XIX. Lisboa, Ed. Arcídia, 1979, 409 p.

Antologia de textos com os comentários críticos do autor a escritos publicados nos princípios do século XIX e que dão informações sobre as características demográficas, económicas, sociais e políticas de Portugal nesta época.

43. Costa, M. GONÇALVES DA-História do bispado e cidade de Lamego. II-Idade Média: Paróquias e Conventos. Lamego, ed. do A., 1979, $633 \mathrm{p}$.

E o $2 .^{\circ}$ volume da obra sobre a história de Lamego (ver BGP 1978 , n. ${ }^{\circ}$ 52), abordando agora o estudo das paróquias da cidade e do seu aro.

44. FERro, MÃria jose PIMENTA - Os judelis em Portugal no século XIV. Lisboa, Guimarñes \& C. ${ }^{a}$ Editores, 1979, 207 p., bibl.

Distribuição das comunas judaicas e papel dos judeus na sociedade e na economia portuguesa dos séculos XIII e xIV. 
45. GONÇALVES, IRIA - "Para o estudo da área de influência do Porto nos fins do século XIV». Revista da Faculdade de Letras. Lisboa, IV série, 2, 1978, p. 383-397.

Através do estudo da origem da população portuense, determinação da área de influência da cidade (na época)..

46. LOBo, ANTónio DE SOUSA SILva COSTA - História da sociedade em Portugal no século XV e outros estudos históricos. Lisboa, Cooperativa Editora, $1979,603 \mathrm{p}$.

Compilação de vários trabalhos publicados pelo autor e em que, do ponto de vista geográfico, interessam essencialmente os elementos sobre a evolução do povoamento (rural e urbano) no século XV $\left(1,^{\mathrm{a}}\right.$ parte da obra).

47. Otrvetra, Aurélio de ARAÚJo - A abadia de Tibães 1630\%80-1813. Propriedade, exploração e produção agricolas no vale do Cávado durante o antigo regime, 2 vols. Porto, Faculdade de Letras da Universidade do Porto, 1979, 798 p., pol.

Depois de uma caracterização geográfica da área, estudo da propriedade, da sua gestão e exploração, produç̃̃es, etc., no periodo considerado.

48. PEREIRA, ESTEVES - Subsidios para a história da indistria portuguesa. Com um ensaio económico-social sobre as Corporações e Mesteres, por Carlos da Fonseca. Lisboa, Guimarães \& C. ${ }^{a}$ Editores, 1979, 191 p.

Reunião de 3 ensaios do autor, incidindo sobre "Corporações Operárias», "Origem e evolução da indústria portuguesa até às invasões francesas» e aA indústria de lanifícios da Covilhã».

49. PEREIRA, Miriam HaLPERN - Revolução, finanças, dependência externa (de 1820 à Convenção de Gramido). Lisboa, Sá da Costa Editora, 1979, $428 \mathrm{p}$.

Antologia em que se pretendem fornecer alguns dos documentos que mostram a transformação da sociedade portuguesa do Antigo Regime para uma sociedade capitalista no século XIX.

50. PINHEIRO, MAGDA DE AVELAR - «Investimentos estrangeiros, política financeira e caminhos-de-ferro em Portugal tra segunda metade do sé-

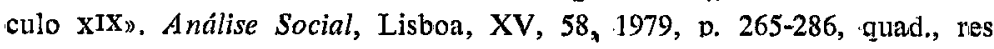
port., e ing.

Para o período 1876-1891, tentativa de periodização das construções de caminho-de-ferro, sua ovolução e financiamento.

51. Pinto, ANtónio Nunes - "Artes e ofícios na freguesia de S. Bartolomeu de Coimbra na última metade do século xvI", in "Actas das 1 Jornadas do Grupo de Arqueologia e Arte do Centro, Coimbra, 1979, p. 205-215 .

A variedade de ofícios numa freguesia dos arrabaldes de Coimbra, em 1567 e 1599 .
52. RaMOs, LUís ANTÓNIo DE OLIVEIRA - "Fomento rural na Estela: fins do século XviII - princípios do século xIX. Boletim Cultural da Póvoa de Varzim, XVI, 1, 1977, p. 27-42, il.

Resenha histórica sobre a política agrícola e informações sobre os tipos de casa, os tipos de culturas e a população da época.

53. REIS, JAIME; MÓNICA, MARIa FILOMENa; SANTOS, Maria dE LOURdes LIMA DOS (coord. de) - O Século XIX em Portugal. Comunicações ao colóquio organizado pelo Gabinete de Investigações Sociais (Novembro de 1979). Lisboa, Ed. Presença, s. d. 478 p.

Importante conjunto de comunicações sobre o período em análise. Entre outros são apresentados temas relativos à industrialização e desenvolvimento, à estrutura da propriedade fundiária e à estrutura social e lutas sociais.

54. ReIS, JAIME - "A 'Lei da Fome': as origens do proteccionismo cerealffero 1889-1914)». Análise Social, Lisboa, XV, 60, 1979, p. 745-793, quad., res. port., fr. e ing.

Através da análise de um conjunto de leis, crio objectivo era a proteç̧ão aos produtores de cereais, $\mathrm{O}$ a mostra as suas consequências em vários aspectos da vida económíca e social.

55. Rodrigues, Cristina M. G.; SOUSA, Joño S. DE; AMARal, J. L. MeNDES DE; ÂNGELo, LIBÂNIo R.; TAPADAs, M. ${ }^{a}$ A.; LeITE, M. ${ }^{a}$ C.; CARDoso, M." DE F. M.; ANDRADE, M. F. DE; ABranTes, M. L. - "O Entre Cávado e Minho, cenário de expansão senhorial no século XIII). Revista da Faculdade de Letras de Lisboa, Lisboa, JV série, 2, 1978, p. 399-440, bib]., map.

Através do estudo das Inquirições de 1258 , análise de vários aspectos do Alto Minho nesta altura: distribuição da população, regime de propriedade, cadastro, etc.

Mapas com a distribuição das propriedades (régias, senhoriais, vilãs), dos padroados e com as áreas principais de influência senhorial.

56. Santos, Candido dos - "A população do Porto de 1700 a 1820 . Contribuição para o estudo da demografia urbana». Revista de História, Porto, I, 1978, p. 281-349, quad., gráf.

Depois de uma demarcação das paróquias da cidade do Porto na época considerada, apresentação de vários elementos sobre a evoluçăo da sua conjuntura demográfica (através das taxas, crises, etc.) e sobre a repartição profissional, por freguesia.

57. SOUSA, FERNANDo ALBERTO PERFIRA DE - A pópulação portuguesa nos inicios do sẻculo XIX. Porto, Faculdade de Letras, 1979, 2 vols., 803 p. pol. (dissertação de doutoramento).

Através dos recenseamentos de 1801-1802, estudo do estado e dos movimentos da população portuguesa nesta época. 
PRE-HISTÓRIA E ARQUEOLOGIA

58. Cardoso, J. L.; Penalya, C. - "Vestígios de Praia Calabriana com indústrias da 'Pebble Culture' no Alto de Leião - Paço de Arcos». Boletim da Sociedade Geológica de Portugal, Lisboa, XXI, 2-3 1979, p. 185196, il., bibl, res. port. e fr.

Noticiam-se vestígios de plataforma de abrasão marinha a $150 \mathrm{~m}$ no Alto de Leião, contendo seixos talhados e rolados (estádio I da «Pebble Cultures marroquina). Pela sua posição, esta praia deverá ser considerada Calabriana e constitui a mais antiga estação paleolítica conhecida até agora em Portugal.

59. G. E.P. P. - "Estudo do Paleolítico da Área de Ródão», O Arqueólogo Português, Lisboa, III,7-9, 1974/77, p. 31-47, il. res. fr.

Com a finalidade de enquadrar os dados da arqueologia no seu contexto geológico, estudo de vários níveis de terracos \& horizontes coaluvionares e suas relações com observações já feitas no mesmo rio em Espanha (Toledo).

As indústrias existentes e sua cronologia.

60. Gonçalves, Vítor dos Santos; Pereira, ANa Ramos - "Considerações sobre o espólio neolítico da gruta dos Carrascos. Monsanto, Alcanena»». O Arqué́logo Português, Lisboa, III, 7-9, 1974/77, p. 49-87, il., res. fr.

Necrópoles megalíticas nas grutas do Maciço Calcário Estremenho.

61. GONÇALVES, JOÂO LUDGERO MAR凤UES - "O monumento pré-histórico da Praia das Maçãs. Arquitectura e Cerâmica pré-campaniforme». Boletim Cultural da Assembleia Distrital de Lisboa, Lisboa, 85, 1979, p. 125-135, il., bibl.

História da descoberta e descricão do material encontrado num conjunto sepulcral implantado no calcário e aue se integra no complexo das necrópoles do Neolítico Final e do Calcolítico em. Portugal.

62. GONÇALVES, JOÂO LUDGERO MARQuES - "Os povoados neo e calcolíticos da Peninsula de Lisboa». Boletim Cultural da Assembleia Distrital de Lisboa. Lisboa, 85, 1979, p. 137-162, il.

Com o intuito de obter informacões sobre as características socio-económicas das sociedades pré-históricas, inventário dos povoados análise das fortificações e casas (ou cabanas) na área de Lisboa (concelhos de Sintra, Cascais, Oeiras, Amadora, Lisboa e ainda parte de Mafra, Loures e Vila Franca de Xira).

63. Penalva, C. - «O Paleolítico do Cabo Sardão. Contribuição para o estudo da "Pebble Culture" de tradição africana». Comunicações dos Serviços Geológicos de Portugal. Lisboa, 65, 1979, p. 225-229, il., res. port. e fr.

Notícia da descoberta de uma estação no Baixo Alentejo, a $45 \mathrm{~m}$ de altitude (limite máximo da transgressão do Tirreniano I), apresen- tando indústrias paleolíticas (é o único local, até hoje conhecido nesta zona costeira, que possui vestígios de artefactos deste período).

64. Penalya, C. - "A "Pebble Culture" de tradição africana em Portugal. O estilo lusitaniano». Comunicações dos Serviços Geológicos de Portugal, Lisboa, 65, 1979, p. 215-223, il., qua., res. port. e fr.

Depois de considerações várias sobre a faceta lusitaniana (predominantemente costeira) o autor enumera, em Portugal, locais onde aparece esta fácies.

65. SERRÂ, EDUARDO DA CUNHA - "As gravuras rupestres do Vale do Tejo". Ocidente, Lisboa, 1979 (n. ${ }^{\circ}$ especial), p. 5-9, bibl.

Breve síntese e localização dos principais conjuntos de gravuras rupestres no vale do Tejo.

66. Soares, Joaquina; Silva, Carlos Tavares Da - "O grupo de Palmela no quadro da cerâmica campaniforme em Portugal». O Arqueólogo Português, Lisboa, III, 7-9, 1974-77, p. 101-112.

Características e distribuição do horizonte campaniforme em Portugal. A posição do grupo de Palmela correspondendo à decadência dos antigos "entrepostos» e ao desenvolvimento de popularões indígenas.

67. Tavares, António Augusto-Expressões do megalitismo nas Beiras. Viseu, Assembleia Distrital de Viseu, 1979, 29 p. il.

Através do estudo de alguns dolmens melhor conhecidos, tentativa de sistematização do fenómeno dolménico da região (parte das Beiras Alta e Litoral); comparações.

\section{HISTÓRIA DO DESCOBRIMENTOS}

68. Costa, Manuel Fernandes - As navegações atlânticas no século XV. Lisbon, Instituto de Cultura Portuguesa, 1979, 116 p.

Pequeno livro de divulgação em que são analisadas as condições e os meios de navegação no Atlântico (processos, cartas, tipo de barcos). as primeiras viagens Juso-castelhanas no século XvI e a política peninsular de então.

\section{GEOGRAFIA FISICA}

CLIMATOLOGIA

69. Godinho, . Silvério Figueiredo - "Contribuicão para o conhecimento do regime das chuvas em Portugal Continental». Revista do Instituto $\mathrm{Na}$ cional de Meteorologia e Geofísica, Lisboa, 1, 2-3, 1979, p. 95-117, res. port. e ing. 
Através da comparação entre as precipitações médias mensais (para períodos de 10 e 30 anos), distribuicão da precipitação ao longo do ano e evolução do regime das chuvas, de 1900 a i1970, em Portugal Continental.

70. Mounier, J. - "Les origines du passage du domaine océaniaue au domaine méditerranéen dans la Penínsule Ibérique». Méditerranée, Marseille, 3, 1979, p. 3-17, il., bibl. res. fr. e ing.

Importância dos factores geográficos (nomeadamente a altitude e a presença de uma camada de ar quente sobre a Península) na modificação das condições climáticas à escala regional.

71. BetTencourt, Manuel L. - "Erosão hídrica na bacia do Mondego». Revista do Instituto Nacional de Meteorologia e Geofisica. Lisboa, 2, $1-2,1979$, p. 91-129, res. port. e ingl.

Depois de considerações sobre os mecanismos de erosão hídrica (solo, relevo, vegetação, precipitaçóes, etc.), apresenta os valores calcula. dos da erosão hídrica nas bacias do Mondego, Dão, Alva e Ceira.

\section{FIDROLOGIA}

72. FARIA, J. M. DA ROCHA; MAChADO, M. J. SOUSA - "Contribuiçño para o estudo hidroclimatológico da bacia hidrográfica do rio Vouga». Revista do Instituto Nacional de Meteorologia e Geofisica, Lisboa, 2, 1-2, 1979, p. $3-89$, res. port. e ing.

Depois de uma apresentação geográfica da bacia do Vouga, sua caracterização hidroclimatológica (através da análise dos valores médios dos principais elementos climatológicos e hidrológicos da região).

Cálculo do balanço hídrico e sua relaçĩo com o balanço energético.

73. Plano de regularizaçño do rio Tejo. Monografia - Lisboa, Dịrecção-Gera] dos Recursos e Aproveitamentos Hidráulicos, 1978, 39 p. pol., gráf.

Valores hidrométricos registados em grandes cheias (1876 a 1978) nas estnções do Tejo.

GEOMORFOLOGIA

74. Brrot, P. - "Plateaux et montagnes de la Beira Septentrionale». Méditerranée, Marseille, 3, 1979, p. 93-94.

Recensão da tese de A. de Brum Ferreira "Planaltos e Montanhas do Norte da Beira. Estudo de Geomorfologia” (n. ${ }^{\circ} 86$ da Bibliografia Geográfica de Portugal. 1978, Finisterra, XIV, 28).

75. Birot, Pierre; Daveau, Suzanne; Ferreira, António de Brum; Godard, Alain; Grelou-Orsini, Camille; RibeIro, Orlando- "Compte rendu d'une excursion de géomorphologie dans le Portugal Central (Mai 1976) - Chronique». Mediterranée, Marseille, 3, 1979, p. 59-70, il. bibl. Observações e reflexões de uma excursão realizada em Portugal Central por um grupo de geógrafos portugueses e franceses.

76. Coude - Gaussen, Genevieve - Les Serras da Peneda et do Gerês Minho-Portugal). Formes et formations d'origine froide en milieu granitique. Paris, Université de Paris (Pantheon-Sorbonne), 1979, 607 p. pol., map., quad, gráf. (These de Doctorat de $3^{\theta}$ cycle).

Estudo das formas glaciárias e da evolução do relevo nas serras da Peneda e do Gerês. O estudo é acompanhado de abundante cartografia e já foi objecto de recensão crítica por parte de J. Nicod (Mediterranée, 36, 3, 1979, p. 100).

77. Daveau, S. - «Progrès récents des connaissances sur la géologie et la géomorphologie du Portugal». Méditerranée, Marseille, 3, 1979, p. 85-91.

Descrição e caracterização das obras mais importantes (livros e mapas) relativas à geologia e geomorfologia de Portugal.

78. FERREIRA, ANTÓNIo DE BRUM - "Os mantos de alteração e o modelado das regiões graníticas: ideias recentes e orientações de pesquisa». Finisterra, Lisboa, XIV, 28, 1979, p. 218-244.

Projecto de investigação sobre as relações entre a alteração das rochas e o modelado nas regióes graníticas de Portugal. Métodos, bibliografia, exemplos.

79. Gullemot, E. - Le litoral de la région de Faro (Portugal). Étude de morphologie littorale. Paris, Université de Paris, Sorbonne, s. d., 129 p. pol., res, fr. (Mémoire de maîtrise).

Depois de caracterizar a região o a. estuda a génese das formas litorais da área de Faro (desde o começo do cordão de Ancão até à ilha de Armona) e a sua dinâmica actual.

80. MARques, M. MONTEIRo - "Contribuição geomorfológica para o estudo da génese, evolução e conservação dos solos em Portugal».

1 - Primeiras observações sobre a superfície de Santiago do Escoural. Anais do Instituto Superior de Agronomia, Lisboa, XXXVII, 1977, p. 65-80 , il,, res, port., fr. e ing.

Através do estudo das formas e materiais constituintes do relevo, análise das heranças paleoclimáticas da região (concelho de Montemor-o-Novo-Alentejo).

81. MOUGENoT, D; VANNEY, J.-R. - "Cartographie géomorphologique de la plate-forme continentale du Portugal et de ses abprds». Bulletin Société Géologigue de France, 20, 5, 1978, p. 785-789. il.

Identificação do relevo da plataforma continental e elaboração de mapas batimétricos e geomorfológicos (na escala 1:150 000) numa tentativa de apresentar os dados fisiográficos que têm sido colhidos. 
82. RAYNAI, RENE - "Observations sur le Quaternaire continental et sa morphogenése dans le Sud et le Centre du Portugal». Finisterra, Lisboa, XIV, 28, 1979, p. 189-217, il. res. ingl

Interpretação de observações realizadas no Alentejo, Algarve e Cordilheira Central (região da Lousã) à luz da experiência mediterrânea do autor.

Quadro com a evolução morfo-climática Quaternária nos diversos domínios mediterrâneos.

\section{GEOLOGIA E SEDIMENTOLOGIA}

83. AIRES-Barros, L. - "Actividade ígnea pós-paleozóica no continente português (elementos para uma sintese crítica)». Ciências da Terra, Lisboa, 5, 1979, p. 175-214, il., bibl., quad., res. port., fr. e ingl.

Referidos os maciços sub-vulcânicos de Sintra, Sines, Monchique, o complexo basáltico de Lisboa e várias outras manifestações filonianas. Correlações petrológico-geoquímicas entre estas formações ígneas e entre a sua génese e a abertura do Atlântico Norte.

84. ANTunes, M. T. - „Ensaio de síntese crítica acerca do Cretácico Terminal e do Paleogénico de Portugal». Ciências da Terra, Lisboa, 5, 1979, p. 145-174, bibl., res. port., fr. e ingl.

Sintese do estado actual dos conhecimentos sobre o período assinalado em título, com base na análise de bibliografia e em observações do autor.

85. Aspectos geológicos de Portugal: Norte / Centro / Sul / Açores / Madeira. Lisboa, Ministério da Educação e Cnltura - Instituto de Tecnologia Educativa, s. d., 44 p.

Conjunto de diapositivos, relativos aos principais aspectos da geologia de Portugal Continental e Insular, ordenados por regiões, tipos de rocha, características geomorfológicas, etc. São acompanhados de uma sugestão didácticn respeitante ao estudo de uma região dos arredores de Lisboa.

86. Azevedo, Teresa M.; Cardoso, João L.; Amorim, Ana B.; Figudiras, JORGE - "Nota sobre paleocorrentes na formação vermelha de Marco Furado (Peninsula de Setúbal). Boletim da Sociedade Geológica de Portugal, Lisboa, XXI, 2-3, 1979, p. 197-201, res. port. e fr.

Tentativa de determinação da génese e da cronologia da uformação vermelha», através do estudo das paleocorrentes (sobre o mesmo problema e no mesmo n. ${ }^{\circ}$ desta revista, ver o artigo de Teresa M. Azevedo: "A formação vermelha de Marco Furado", p. 151-162).

87. Berthou, P. Y.; LAUverJat, J. - «Essai de synthèse paleogéographique et palèobiostratigraphique $\mathrm{du}$ bassin occidental portugais an cours du Crétace supèrieur». Ciências da Terra, Lisboa, 5, 1979, p. 121-144, il., bibl., res. port., fr. e ingl.

Através do estudo dos ambientes de sedimentação, tentativa de reconstituição global da evolução da bacia.
88. BoIllot, G.; MALod, J. A.; MOUGenot, D. - "Évolution géologique de la marge ouest-ibérique». Ciências da Terra, Lisboa, 5, 1979, p. 215-222, il., bibl., res. port. fr. e ingl.

Síntese que resume um conjunto de trabalhos dos autores sobre a orla da Península Ibérica.

89. "Distrito antimonífero Dúrico-Beirão: mineralização de $\mathrm{Sb}-\mathrm{Zn}-\mathrm{Pb}$, no jazigo do Ribeiro da Igreja (Valongo, Norte de Portugal». Memórias e Noticias, Coimbra, 82, 1976, p. 67-77, map., quad., res. port., fr. e ingl. Estudo do jazigo e sua comparação com outros localizados na mesma área

90. GaLletTi, REgINE Crosaz - „Étude stratigraphique et macropaléontologique du Cenomanien calcaire de la rêgion de Vila Nova de Ourém». Comunicações dos Serviços Geológicos de Portugal, Lisboa, 65, 1979, p. 47-104, il., res, fr. e ingl.

Através da análise detalhada de 16 cortes efectuados na região, estudo do Cenomaniano representado.

91. JONET, S. - «Le Tortonien Supérieur (T vII b) des environs de Fonte da Telha (Peninsula de Setúbal) et ses faunes». Comunicações dos Serviços Geológicos de Portugal, Lisboa, 63, 1978, p. 13-51, i1. e 65, 1979, p. 105 -130 , il., res. port., fr. e ing.

Depois de uma 1. parte em que é feita uma breve descrição geológica da área, o a. estuda a fauna para, através dela, retirar conclusões sobre a profundidade e temperatura das águas do Tortoniano.

92. Manuppelia, G.; Moreira, J. C. Baracó - „Argilas da região entre Rio Maior e Alcobaça (Sinclinal de A-dos-Francos). I- Geologia e amostragem». Estudos, Notas e Trabalhos do Serviço de Fomento Mineiro. Lisboa, XXIII, 3-4, 1977, p. 147-157, quad., res. port, fr. e ingl.

Enquadramento geológico da região e características das formações geológicas aflorantes.

93. MANUPPELIA, GYUSEPPE; MOREIRA, J. C. BAIACÓ - "Calcários e dolomitos da área de Sesimbra - Cabo Esvicheln. Estudos, Notas e Trabalhos do Serviço de Fomento Mineiro, Lisboa, XXIII, 3-4, 1977, p. 263-279, quad., map., res. port., fr. e ingl.

Enquadramento geológico regional e acidentes tectónicos que afectaram a área. Estudo pormenorizado dos calcários jurássicos.

Estabelecimento de áreas preferenciais de exploração, em relação com os tipos específicos de indústria utilizadora.

94. Manupuela, G.; Moreira, J. C. Balacó - "Calcários e dolomitos da Serra da Picavessa (Loulé)n. Estudos, Notas e Trabalhos do Serviço de Fomento Mineiro, Lisboa, XXIII, 3-4, 1977, p. 233-422, quad., res. port., fr. e ingl.

Descrição litológica e estudo do comportamento auímico das formações da serra (uma área muito complexa tanto no aspecto geológico como tectónico). 
95. MOUgenot, D.; MONTUIRO, J. H.; DUPEUBle, P. A.; MALOD, J. A "La marge continentale sud-portugaise: évolution structurale et sedimentaires. Ciências da Terra, Lisboa, 5, 1979, p. 223-246, il., bibl., res. port., fr. e ingl.

A evolução estrutural e sedimentar da margem continental portuguesa a sul de Setúbal é reconstituída a partir do estudo de perfis sísmicos e de amostras colhidas

96. Mouterde, R.; Rocha, R. B.; Ruget, Ch.; Tintant, H. - «Facies, biostratigraphie et paléogéographie du Jurassique Portugais». Ciências da Terra, Lisboa, 5, 1979, p. 29-52, il., bibl., res. port., fr. e ingl.

Síntese que se propõe traçar a evolução paleográfica da orla ocidental portuguesa no decurso do Jurássico.

97. Mouterde, R.; Rocha, R. B.; Ruger, Ch. - "Stratigraphie et faune du Lias et de la base du Dogger au Nord du Mondego (Quiaios et Brenha). Comunicações dos Serviços Geológicos de Portugal, Lisboa, LXIII, 1978, p 83-104, res. fr.

Pela descrição das camadas do flanco Norte da Serra da Boa Viagem se estabelece uma estratigrafia detalhada do Lias e do Aaleniano, com inventário de faunas. (A fauna de ammonites permite correlações precisas).

98. PaIs, J. - «Notes sur la géologie et la paleontologie du Miocècene de Lisbonne. XXI - Primeira caracterização de dinoflagelados dos niveis mais baixos da série miocência de Lisboa». Ciências da Terra, Lisboa, 4, 1978, p. 31-46, il., res. port., fr. e ingl.

Através do estudo litoestratigráfico, datação de um novo ciclo sedimentar no Miocénico inferior de Lisboa.

99. Palain, C - "Connaissances stratigraphiques sur la base du Mésozoique Portugais». Ciências da Terra, Lisboa, 5, 1979, p. 11-28, il., bibl., res. port., fr. e ingl.

Características do Triassico e Liassico inferior e localizacão dos principais afloramentos em Portugal (áreas diapíricas e Algarve).

100. Perdigão, Jacinto CORReia - "O Devónico de Dornes (Paleontologia e estratigrafia)». Comunicações dos Serviços Geológicos de Portugal, Lisboa, 65, 1979, p. 193-199, il., res. port." e fr.

Estudo das jazidas devónicas descrevendo a sua fauna e o seu facies e comparando com outras jazidas portuguesas e estrangeiras.

101. Ramos, J. M. Farinha; Oliveira, J. M. SANTos- “Prospecção geológica e geoquímica na área scheelítica de Vila Nova de Foz Côa (Norte de Portugal)", Estudos, Notas e Trabalhos do Serviço de Fomento Mineiro, Lisboa, XXIII, 3-4, 1977, p. 107-145, il., quad., map., res. port. e ingl.

Estudo a nível regional e local.

Interesse mineiro da airea de Freixo de Numão.
102. REY, J. - «Le Crétacé i-férieur de la margè atlantique portugaise: biostratigraphie, organisation sèquentielle, évolution paleogéographique». Ciências da Terra, Lisboa, 5, 1979, p. 97-120, il,, bibl., res. port., fr. e ingl. Breve descrição das principais formações do Cretácico inferior da Estremadura e Algarve e, através da distribuição do fácies, reconstituição da paleogeografia.

103. Ribeiro, A; ANTUNes, M. T.; FERreira, M. P.; ROCHA, R. B.; SOARES, A. F.; Zbyszewsky, G.; Almeida, F. Moitinho de; Carvalfio, D. DE; Monteiko, J. H. - Introduction à la géologie générale du Portugal. Lisboa, Serviços Geolćgicos de Portugal, 1979, 114 p., il., bibl.

Além de traçar o quadro estrutural e geotectónico da Península e do Maciço Hispérico (e de o siturar no quadro europeu), este estudo faz, para Portugal, uma reconstituição paleogeográfica por ciclos orogénicos. $\mathrm{Na}$ última parte são analisados os recursos naturais. Inclui também a geologia das ilhas Atlânticas. Possui ilustração abundante.

104. ROCHA, R. B; MARQues, B. - "Le Jurassique de l'Algarve (Portugal): esquisse stratigraphique et évolution paléogeographique». Boletim da Sociedade Geológica de Portugal, Lisboa, XXI 2-3, 1979, p. 137-151, bibl., res. port. e fr.

Nota em que é apresentada uma síntese dos conhecimentos actuais da cronoestratigrafia e da evolução paleogeográfica dos terrenos jurássicos do Algarve.

105. Teixeira, Carlos - "Georges Zbyzzewski - O Homem e o Cientista». Comunicaçóes dos Serviços Geológicos de Portugal, Lisboa, 65, 1979, p. 3-27.

O autor enumera os aspectos mais salientes da obra de G. Zbyszzewski (especialmente importantes no domínio da geologia e arqueologia do Quaternário e da estratigrafia das orlas sedimentares). Bibliografia exaustiva dos seus estudos em Portugal.

106. Teixeira, Carlos - "O Precâmbrico de Portugal".Boletim da Sociedade Geológica de Portugal, Lisboa, XXI, 2-3, 1979, p. 129-136, bibl., res. port. e fr.

Sintese do estado actual dos conhecimentos do Precâmbrico do W Peninsular lbérico.

107. Teixeira, Carlos - «Plio - Plistocénico de Portugal».Comunicações dos Serviços Geológicos de Portugal, Lisboa, 65, 1979, D. 35-46, bibl., res. port. e fr.

Localização e caracterização dos principais afloramentos.

108. WILSON, R. C. L. - "A reconnaissance study of Upper Jurassic sediments of the Lusitanian basin». Ciências da Terra, Lisboa, 5, 1979, p. 53-84, il., bibl., res. port., fr. e ingl. 
Evolução do Jurássico Superior da bacia lusitaniana que está relacionada com a fase de rift que precedeu a separação entre a Ibéria e o Gand Banks).

Síntese de trabalhos publicados; localizações.

AMBIENTE, CONSERVAÇÃO E POLUIÇÃO

109. Carneiro, Ana PaUla - Poluição atmosférica na indústria do cimento Porto, Serviço de Estudos do Ambiente, 1979, 83 p. pol., q̣uad., gráif.

Identificação e localização dos poluentes emitidos para a atmosfera. Descrição sumária das unidades produtoras e tentativa de quantificação das suas emissões.

110. FERnaNdes, ANTónio Luís; SoUsa, Maria Eduarda T. DE; SILveira, MARIA ISABEL PORTUGAL DA; GRANCho, MARIA AUGUSTA - Lagoa de óbidos. Controle da sua polluição. [Lisboa], Direcção dos Serviços de Controle da Poluição, 1977, 57 p., pol., quad., map., bibl.

Depois de uma breve introdução em que se apresenta a dinâmica das marés e as principais fontes da sua poluição, os A. estudam o estado actual da Lagoa através de análises químicas, biológicas e bacteriológicas.

111. JUDICE, EUGÉNIO - "O parque natural algarvio». Natureza e Paisagem, Lisboa, 8, 1979, p. 2-8, il.

Características, potencialidades e importância económica das actividades exerciclas; valores a preservar.

112. NEves, C. M. L. BaEta - "Da história do Paul da Ota e a defesa das "zonas húmidas". Anais do Instituto Superior de Agronomia, Lisboa, XXXVII, 1977, p. 257-274, il., bibl., res. port. e fr.

Através da análise de alguns documentos antigos, tentativa de reconstituição e evolução deste paúl.

113. Silveira, AdRIANo-Poluição atmosférica na bacia do rio Sousa-inventário. Porto, Serviço de Estudos do Ambiente, 33 p. pol., quad. gráf., mapas.

Inventário de fontes e emissões de poluentes na bacia do Rio Sousa. Os valores utilizados são posteriores a 1975 .

114. Sousa, Mário da Silva e; Santos, Arlitte Domingues dos - Sobre o aproveitamento de lixos urbanos. Caso particular do tratamento de lixos pela sociedade do aproveitamento industrial de Matos. Lisboa, Laboratório Rebelo da Silva, 1977, 26 p., pol., quad.

Formas de aproveitamento dos lixos, seus processos de transformação e aplicação à agricultura. Apreciação dos problemas nos vazadouros de Braga e Coina.

\section{GEOGRAFIA HUMANA}

115. FREUND, BODO - «Portugal». Stuttgart, E. Klett, 1979, 149 p., 1 map., quad., fig., bibl.

Pequeno manual, bem documentado, sobre os aspectos e os problemas geográficos actuais de Portugal.

116. GASPAR, JORGE (dir.) - Portugal em mapas e números. Lisboa, Livros Horizonte, 1979, $189 \mathrm{p}$.

Quadros e gráficos apresentando vários elementos (climáticos, populacionais, agrícolas, industriais e sócio-económicos) que poderão servir de base a estudos posteriores (para Portugal Continental, Açores e Madeira).

117. REIS, MARIA ALICE - Portugal-sintese geográfica. Lisboa, Direç̧ão-Geral da Divulgação, 1979, 51 p., il.

Livro de divulgação em que se salientam os contrastes físicos e humanos entre o litoral e o interior e entre o Norte e o Sul do País.

(Também publicado em francês).

118. RIBEIRo, ORLANDO - "O Brasil: evolução singular no império português». Revista Portuguesa de História, Coimbra, XVII, 1977, p. 231-243.

Notas sobre a evolução do Brasil desde o início da colonização e sobre as características do português como trabalhador no Brasil

\section{HABITAÇÃO E POVOAMENTO}

119. Ribeiro, ORLando-Geografia e Civilização. Temas Portugueses. [Lisboa], Livros Horizonte [1979], 161 p., il.

E $2 .^{a}$ edição da obra publicada em 1961 .

120. MOUTINHO, MARIO C. - A arquitectura popular portuguesa. Lisboa, Editorial Estampa, 1979, 186 p., il., map.

Depois de uma introdução geográfica, características da arquitectura popular nas regiões Norte, Centro-litoral, Alentejo e Algarve (tipos de povoiamento e de casas, cores utijizadlas, arnuamentos, etc.).

ETNOLOGIA E TOPONIMIA

121. BARBOSA JORGE - "Toponímia da Póvoa de Varzim». Boletim Cultural da Póvoa de Varzim, Póvoa de Varzim, XVIII, 1, 1979, p. 9-68, il.

Continuraç̃̃o de artigos anteriores (ver na B. G.P. - 1978, o n. ${ }^{0}$ 105. Finisterra, X1V, 28); trata aqui dos topónimos em $\mathrm{S}$.

122. Cabral, António (coord.) - Trís-os-Montes e Alto-Douro. Vila Real, Ministério da Comunicação Social - Direcção-Geral da Divulgação, 1979, 143 p., il. 
A partir da selecção de textos, aspectos do artesanato, da economia, dos usos e costumes, do património artístico e do trabalho, na região mencionada.

123. Cardos, Mário-Apontamentos de etnografia la Beira Alta (Ręião de Lafões). Guimarães, Ed. da Sociedade Martins Sarmento, 1975, 84 p., il.

Referências a usos e costumes, aos instrumentos utilizados nos trabalhos agrícolas, etc.

124. Correia, AlberTo - «Brezas do Montemuro e cestas de palha de Alvito». Beira Alta, Viseu, XXXVIII, 2, 1979, 1D. 259-299. (brezas).

Descrição do fabrico de cestos feitos com a palha de centeio

125. Correta, AIberTo - «Esteireiros da Lageosa do Dão. Cestos de estejra». Beira Alta, Viseu, XXXVIII, 1, 1979, p. 32-72

Descrição das matérias-p̣imas empregadas e das várias fases de fabrico dos cestos.

126. CORREia, ALBERTo - A serra de Montemuro-Meio físico e etnográfico. Coimbra, G. A. A. C., 1979, p. 91-99 (Sep. uActas das I Jornadas do Grupo de Arqueologia e Arte do Centron).

Depois de localizar a serra, tenta o A. mostrar as relações entre o homem e a natureza (do ponto de vista etnográfico).

127. FONTES, ANTÓNIO LOURENÇO-Etnografia Transmontana. 1-Crenças e Tradições de Barroso. Vilar de Perdizes (Montalegre), ed. do a., 1979, 175 p., bibl.

É a $2 .^{a}$ ed., corrigida e aumentada, da publicação de 1974.

128. Geraldes, ALICE-Castro Laboreiro e Soajo. Habitação,vestuário e trabalho da mulher. Lisbca, Serviço Nacional de Parqulues, Reservas e Património Paisagístico, 1979, 95 p., il.

A habitação. tradicional, sua evolução e significado social.

A propósito das actividades da mulher nesta região, descrição dos vários trabalhos agrícolas ao longo do ano, sua terminologia, usos e costumes,

129. Guerreiro, M. Viegas - «Pastoreio e Tecelagem em Pitões de Júnias». Natureza e Paisagem, Lisboa, 7, 1979, p. 2-10, il.

Notas etnográficas sobre duas importantes actividades da população das terras fronteiriças do Gerês.

130. LOPES, ANA MARIA SIMÕES DA SILVA - "O vocabulário marítimo português e o problema dos mediterraneísmos». Revista Portuguesa de Filologia, Coimbra, xvit, 1-2, 1975-78, p. 211-383, res. fr.

Neste art. ${ }^{\circ}$ (já em continuação) fazem-se comparações entre o litoral algarvio e a costa oeste portuguesa mostrando-se a influência de vários gru- pos e simultaneamente, a originalidade do Algarve nas actividades piscatórias.

Comparações entre as embarcações e processos de pesca portugueses e os dos outros países mediterrâneos.

131. MAIA, Clarinda DE AZEvEdo - "Os falares do Algarve (inovação e conservação). Revista Portuguesa de Filologia, Coimbra, XVII, 1-2. 1975-78, p. 1-205, bibl., map., res. fr.

A individualidade dos falares algarvios e suas afinidades com os do Baixo Alenteio e Minho. Problemas da influência árabe e espanhola.

São apresentados mapas com a distribuicãa dos factores de natureza fonética, morfológica e lexical.

132. PoLANAH, Luís - «Castro Laboreiro de relance». Minia, Braga, 2.9 série, II, 3, 1979, p. 198-222, il.

Características da comunidade e suas transformações recentes.

133. Ribeiro, JosÉ ANTóNIo PINTO - «Estudo linguísticoi e etnográfico-folclórico sobre a freguesia da Estela (Póvoa de Varzim)n. Boletim Cultural da Póvoa de Varzim, xvilı, 1, 1979, p. 69-103, il.

Continuação de artigos anteriores (ver na Bibliografia Geográfica de Portugal-1978, o n.0 111 - Finisterra, xIv, 28).

134. SERRA, PEDro CUNha - "Estudos Toponímicos».Boletim de Filologia, Lisboa, xxy, 1-4, 1976/79, p. 263-274.

Análise de alguns topónimos, nomeadamente Penedono, Brancelhe, Bagueixe, Lixosa e outros; sua origem e distribuição em Portugal.

135. SOARES, MARIA MICAELA - "Mulheres da Estremadura". Boletim Cuitural da Assembleia Distrital de Lisboa, Lisboa, 83, 1977, p. 295-337, il., bibl.

A vida quotidiana das mulheres da Lezíria Ribatejana. Elementos sobre a casa, a alimentação, o vestuário, as crenças e costumes, o trabalho, etc.

136. Vasconcelos, J. LeIte DE - Cancioneiro Popular Português (coord. e notas de MARIa ARMinda ZaLUar Nunes), vol. II. Coimbra, por ordem da Universidade, $1979,535 \mathrm{p}$.

Mais uma compilação dos importantes trabalhos de Leite de Vasconcellos. Neste volume, entre outros, são recolhidas cantigas sobre as idades, as superstições, os usos e costumes da vida quotidiana, da familia, etc.

\section{GEOGRAFIA E POPULACAO}

137. ALMEIDA, Carlos - Portuguese Immigrants. San Leandro (Califórnia), Supreme Council of U. P. E. C., 1978, 279 p., il,, bibl. 
cias combinadas dos cônjuges” (e agrupados em períodos de 5 anos), tentativa de análise das relações interdistritais.

Alguns elementos sobre a história da instalação de emigrantes açorianos na América do Norte. Causas da partida e condições sócio-culturais na nova sociedade.

Notas biográficas sobre alguns emigrantes.

138. AlMEIDA, MARIA ADELAIDE $S$ - " "A poupança dos emigrantes e a sua aplicação». Boletim da Comissão de Planeamento da Regiẫo Centro, Coimbra, 8, 1979, p. 45-53.

Principais medidas em vigor destinadas a aplicação das poupanças depositadas pelos emigrantes. Considerações sobre a sua importância para o desenvolvimento regional do país.

139. AlPALhÁ, J. AN'Tónio; ROSA, VÍctor M. P. DA-Les portugais du Québec. Eléments d'analyse socict-culturelle. Ottava, édi. de l'Université d'Ottawa, 1979, 320 p., quad., bibl.

Abordados, entre outros, os problemas da família, da escola, do trabalho, da saúde, da religião, da vida comunitária desta comunidade portuguesa. Camparações entre o meio de origem e o de destino.

140. Boura, ISABEL; JACINTO, RUI - «Potenciais demográficos e níveis de polarização gravitativa na Província das Beiras». Boletim da Comissão de Planeamento da Região Centro, Coimbra, 7, 1978, p. 13-63, i]., quad.

(Determinaçãcl, sob o ponto de vista demográfico, dos pólos de maior dinâmica e das áreas mais deprimidas da região.

Hierarquia das sedes de concelho e áreas de influência.

141. Carrilo, Maria Joș - 1979, Ano Internacioal da Crianca (Colectânea de dados esstatisticos relativos à situação da criança em Portugal). Lisboa, Instituto Nacional de Estatística, 1979, 68 p., quad., res. port., fr. e ingl. ("Estudos», 55).

Para o periodo 1967-1977, procura mostrar-se a evolução da criança portnguesa (Continente, Açores e Madeira) nalguns dos seus aspectos demográficos (natalidade, mortalidade, emigração) e sociais.

142. Cavaco, Carminda; Medeiros, Carlos Alberto-Aspectos geográficos da evolução demográfica de Portugal Continental depois do último censo. Lisboa, Centro de Estudos Geográficos, 1979, 102 p. pol., il. (Estudos de Geografia Humana e Regional, A 1)

Evolução da população, estruturas das taxas (natalidade, mortalidade) e dos movimentos migratórios. O estudo é feito a nível global e distrital e compreende o periodo 1970-1977 (para a maioria dos elementos).

143. FERRão, JOÃo MANUEL MACHADO - Interacção regional e divisão territorial do trabalho. Lisboa, Centro de Estudos Geográficos, 1979. 74 p. pol., il., quad., res. fr. e ingl. (Estudos para o Planeamento Regional e Urbano, 8).

Com base nos elementos publicados, desde 1955, nas Estatistickas Demográficas sob a rubrica «Casamentos celebradçs segundo as residên-
144. FonseCA, IsABeL - «A População da Aldeia da Luz e a Barnagem do Alqueva». Natureza e Paisagem, Lisboa, 8, 1979, p. 26-32, i1.

Através de testemunhos directos, análise dos anseios e problemas da população de uma aldeia alentejana que ficará submersa com a construção da barragem.

145. Guichard, FrançoIs - «Origine et réinstallation des repatriés d'Afrique Finisterra, Lisboa, XIV, 28, 1979, p. 258-268, res. ingl.

Os retornados das ex-colónias fixaram-se sobretudo nas grandes ciclades e nas suas regiões de origem, impedindo assim o despovoamento destas.

146. LAGES, MÁRIO - A Natalidade Portuguesa. Premissas Demográficas, Lisboa, Edições Excelsior, 1979, 118 p., bibl.

$\mathrm{Na}$ tentativa de interpretar a evolução do comportamento de reprodução da família portuguesa, análise das taxas (natalidade, mortalidade, nupcialidade, emigração) e das suas interrelações. A maioria dos cálculos é feita até 1975 e são analisadas as variações distritais das várias medidas.

147. - Migrações pendulares $e$ unidades geográficas de emprego. Lisboa, Centro de Estudos de Planeamento, 1978, 58 p., poll, quad., map. (Estuidos Urbanos e Regionais, 15).

Para o distrito de Leiria (e com base nos dados obtidos, na Caixa de Previdência, análise dos movimentos dos trabalhadores e delimitação das unidades geográficas de emprego (só consideradas as empresas com 5 e mais trabalhadores).

148. Morgado, NUNo ALVES - «Portugal», in «European demography and economic growth), London, Ed. W. R. Lee, 1979, p. 319-339, bibl., quad.

Análise da evolução da população e suas principais causas. A alte-

149. «A mulher no emprego em Portugal». Boletim da Comissão da Condição Feminina, Lisboa, v, 1, 1979, quad., gráf.

Estudo da evolução da actividade feminina entre 1940 e 1970.

150. NASCIMENTO, JOÂO - "Indice de vitalidade e crescimento natural da população portuguesa». Boletim da Comissão de Planeamento da Região Centro, Coimbra, 8,1979 , p. $3-44$, il.

Impcrtância das diferenciações regionais. na taxa de crescimento natural. .

151. NAZARETH, J. MANUEL - $O$ envelhecimento da população portuguesa. Lisboa, Editorial Presença - Gabinete de Investigações Sociais, 1979, 238 p. ração nas correntes de emigração. 
Depois de analisada, por grupos de idade, a desigual repartição da população no país, estudo das causas que levam ao envelhecimento progressivo dessa populaçção (1930-1970).

Aspectos regionais e evolnção provável do fenómeno, no periodo 1970-1980.

152. PORTO, MANUEL CARLOS LOPES - "Emigração e desenvolvimento regional em Portugaln.». Boletim da Comissão de Planeamento da Regiño Centro, Coimbra, 5, 1977, p. 88-124, il., quad.

Impacto da emigração no desenvolvimento regional (nos níveis demográfico e econćmico). Causas do grande fluxo migratório dos anos 60 .

153. Silva, J. Henriques DA; MONIZ, Fernando - "Uma aplicação do método Cohort-Survival a nivel distrital». Planeamento, Lisboa, I, 1, 1978, p. $23-57$, res, port. e ing.

Através do método citado em título, tentativa de determinação da provável evolução dos níveis de mortalidade e fertilidade em cada distrito do Continente, para o periodo 1974-1979. Papel das migrações na estrutura demográfica. Exemplificação com o distrito de Aveiro.

154. TRINDADE, Maria Beatriz Rocha - «Labor-Exporting Countries Portuga1». International Labor Migration in Europe. New York, Praeger Publishers, 1979, p. 164-172, quad.

Breve síntese sobre a emigração portuguesa, desde o seu início até 1975. Características e quantitativos.

155. WISNIEWSKI, J. - "L'immigration: un problème de société». Hommes et Migrations-Documents, Paris, 961-962, 1979, $95 \mathrm{p}$.

Consequências (demográficas e económicas) para a sociedade francesa, das diferentes vagas migratórias através dos tempos.

Numerosos dados (qualitativos e quantitativos) referentes à emigração portuguesa.

\section{GEOGRAFIA AGRARIA}

156. Balabanian, OLIVIER - Les exploitations et les problèmes de l'agriculture en Estrémadure espagnole et dans le Haut-Alentejo. Contribution à l'étude de calmpagnes mediterraneennes. „Limoges, ed. do A., 1979, 984 p., pol., il., bibl., map.

Este estudo (que constitui a tese de doutoramento de Estado do A.) incide sobre as estruturas fundiárias alentejanas e estremenhas e sobre a evolução e transformação dos sistemas de produção agrícolas (agricultura de sequeiro e de regadio).

157. BARRos, AFonso DE- uA Reforma Agrária em Portugal e o desenvolvimento reconómico e social». Revista Critica de Ciências Sociais, Coimbra, 3, 1979, p. 53-74.
Características e consequências da R. A. na transformação e desenvolvimento económico e social do país.

158. Barros, AFonso DE; MENDES, Fernando Ribeiro E MENdes GuiLHerme, colab. - A Reforma Agrária em Portugal. (Das ocupações de terras à formação das novas unidades de produção). Oeiras, Centra de Estudos de Economia Agrária - Fundação Calouste Gulbenkian, 1979, 274 p., gráf., map., bibl., res. port., fr. e ing.

Depois de limitar e caracterizar a região onde a $\mathbb{R}$. A. teve lugar, análise das grandes linhas de evolução do processo social (circunstâncias que levaram à ocupação das terras, formas como estas se concretizaram, condicionalismos que presidiram à formação das novas unidades de produção e características assumidas pelas mesmas).

Consequências sobre as estruturas agrárias. Legislação.

159. Baumfeld, CARLOS Minc; Lemos, JoÃo CARDoso-A agricultura e o desenvolvimento regional. Elementos para o estudo do sector agrícola dos concelhos de Arraiolos, Evora, Mora, Montemor-o-Novo e Vendas Novas. Lisboa, Centro de Estudos Geagráficos, 1979, 200 p. pol., bibl., quad., res. fr. e ingl (Estudos para o Planeamento Regional e Urbar no, 10).

Evolução recente da estrutura agrária na área em estudo: população activa agricola, explorações segundo o tipo de empresa e formas de exploraçãa. Outros assuntos abordados: mecanização e pradutividade, emprego e Reforma Agrária (além de considerações sobre desenvolvimento regional e de uma caracterização e análise da importância do sector agrícola na economia portuguesa entre os anos 50-70).

160. Caryalho, Agostinho DE; RiBeiro, josÉ júlio - Tipologia das explorações agricolas da sub-região viticala de "Torres». Oeiras, Centro de Estudos de Economia Agrária - Instituto Gulbenkian de Ciência, 1979, $78 \mathrm{p}$.

Baseado num inquérito feito a agricultores (sócios da Adega Cooperativa de Dois (Portos), elementos sobre a dimensĩo das explonações, aproveitamento do sola e formas de exploração, estmutura do produto e destino da produçção, mão-de-obra, equipamento e meios de produção. tados.

Em anexo é apresentado o questionário utilizado e os seus resul-

161. Cavaco, Carminda - Alguns aspectos das estruturas agráricts de Portugal Continental. Lisboa, Centro de Estudos Geográficos, 1979, 53 p., pol., il. (Estuddos de 'Geografia Humana e Regional B-2).

Canacteristicas e evolução da agricultura portuguesa desde meados do século; suas carusass e consequências. 
As estruturas fundiárias (a Norte e a Sul do Tejo) antes de 1974; modificações introduzidas pela Reforma Agrária e outnas importantes medidas.

162. Cavaco, CaRminda - “Orientações horto-frutícolas do Baixo Algarve». Estudos Italianos em Portugal, Lisboa, 40-41-42, 1977/78/79, p. 281-339, il., gráf., quad.

Neste estudo recordam-se as orientações tradicionais da horticultura e fruticustura do Baixo Algarve e o seu contributo ipara o abastecimento de Lisboa. Numa $2 .^{n}$ parte, partindo do significado económico destas produçóes una economia agrícola da Praríncia, salienta--se o seu desenvolvimento nos anos 70 , apoiado pela difusão de novas técnicas de forçagem e de novas culturas.

163. CoRdovil, Francisco CaBraL - Estrutura das Explorações Agricolas. $O$ produto agricola bruto como instrumento de análise e determinação. Ensaio para 1968-70. Oeiras, Centra de Estudos de Economia Agrária - Instituto Gulbenkian de Ciência, 1979, 294 p.s çuad., res. port. fr. e ing.

Analisa a utilização do P. A. B. cơmo indicadior da dimensão económica das explorações agrícolas (a nível distrital, no Continente).

164. DRAIN, M. - «La réforme agraire portugaise», Méditerranée, Marseille, $37,4,1979$, p. 41-54, res. fr., ingl, e esp.

Enquadramento político e económico da Reforma Agrária portur guesa e dificuldades na sura aplicação.

165. Henriques, Renano; Hentiques, Tito-A Companhia das Lezírias mito ou realidade? Contribuição para o estuda de um dos mais ignorados processos da história agrária portuguesa. Lisboa, Companhia das Lezírias, 1979, $310 \mathrm{p}$.

Evolução histórica da maior empresa agrícola portuguesa desde a sua constituição (no século XIX), até à sua nacionalização (pós 25 de Abril de 1974). Potencialidades, condicionalismos e perspectivas de desenvolvimento pecuário.

166. Inquérito à apicultura regional (análise preliminar). Porto, Comissão de Planeamento da Região do Norte, 1979, 17 p., pol. + anexos com quad. e map.

Os dados apurados são de 1977 e referem-se a produções, comercialização, distribuição de cortiços e colmeias, evoluçãio e suas causas.

167. Paixão, Carlos Albuquerque - "Caracterização actual e futura dos campos de Baixo Mondego». Boletim da Camissão de Planeamento do Região Centro, Coimbra, 7, 1978, p. 64-105.

Limitações técnicas e económicas dos campos do Mondego com vista ao seu aprdireitamentid hidroagrícola. Dados relativos ao tipo e regime de exploração agrícola, às características do sclo, da populaçño, da economia regional, etc. $O$ problema das cheias e suas consequências.
168. PALMinha, LUís - Contribuição para o estudo dla reestruturação fundiária da área do Douro. Porto, Comissão de Planeamento da Região do Norte, 1977, 57 p.., pol., quad.

Problemas da agriciultura duriense perante a futura entrada de Portugal na C. E. E.

Apresentação da legislação francesa respeitante à alteração da estrutura fundiária.

169. PERTiRa, MARIo-A estrutura agrária portuguesa (1968-1970))-suas relações com a população $e$ a produção agrícolas. Oeiras, Centro de Estudos de Ecionomia Agrária - Instituto Gulbenkian de Ciência, 1979, 283 p., bibl., quad., map., res. port. fr. e ing.

Caracterizaçãol dos pincizais aspectos da estrutura agrária portuguesa no período considerado (estrutura das explonações, características das dirigentes, mão-de-obra, utilização dos capitais, etc.).

Importância do sector agrícola no conjunto da actividade económica nacional.

Análise comparativa dlas situações estruturais e sua evolução (po'r distrito) entre 1960 e 1970.

170. PIRES, C. BORGES - Condições de vida e de alimentação das famílias dos Trabalhadores rurais da freguesia de Albernoa. Oeiras, Centro de Estudos de Economia Agrária-Instituto Gulbenkian de Ciência, 1979. 39, p., bibl., quad.

Estudo baseado num inquérito efectuado em 1977 e em que se pretende apurar a dieta qualitattva e quantitativa da populaçăo rural de uma freguesia do condelho de Beja (através da análise das Receitas e Despesas familiares, e dos géneros da vida).

O estudo integra-se num vasto projejcto de investigação cujol objectivo é a análise das transformações económicas e sociais no sul do $\mathrm{Pa} \mathrm{s}$, após o 25 de Abril.

171. Portugal. Agricultural Sector Survey. Washington, The World Bank, 1978, 323 p., pol., quad., res. ing.

Análise geral do sector agrícola, das reformas agrárias e dos principais projectos de cllesenvolvimento (projectos de irrigação e projectos de desenvolvimento rural em Trás-os-Montes).

172. RoCHA, EDGAR - "Evolução do défice externo agrícola, particularmente no domínio alimentar e suas causas». Análise Social, Lisboa, xv, 60, 1979 , p. $839-857$, bibl., res. port. fr. e ingl.

Depois de uma análise da evollução do défice agrícola, determinação das prováveis causas de estagnação do sector (deficiência da estrutura agrária, ausência de uma política agrícola coerente, impacto da emigração e falta de investimento).

173. SANTA-RITA, Goncalo-Portugal, Agricultura e Problemas Humanos. Lisboa, Terra Livre, 1979,193 p. il. 
Aspectos físicos e humanos do País com maior incidencia nas técnicas de prơdução agrícola e nas modificações operadas pela Reforma Agrária no Alentejo; problemas surgidos.

\section{GEOGRAFIA URBANA}

174. ALARCÃo, JoRGE - «As cirigens de Coimbra».Actas das I Jornadas do Grupo de Arqueologia e Arte do Centro. Caimbra, 1979, p. 21-40.

Através da análise de documentos escritos, da toponímia, dos monumentos, etc., tentativa de reconstituição do "sítio" primitivo de Coimbra; as vantagens da sua "posição».

175. GASPAR, JORGE - Portugal, a terra e o homem-Expressão das cidades. Lisboa, Fundação Calouste Gulbenkian, 1979, 19 p.

Colecção de 296 diapositivos agrupados por províncias e mostrando aspectós vários das cidades portuguesas (incluindo Açores e Madełina). Acompanhada duma memória descritiva.

176. GASPAR, JORGE - «Zentrum und Peripheric im Balilungraum Lissabon». Urbs et Regios, Kasseler Schriften zur Geografie und Planung, Kassel, 12,1979 , p. $1-133$, il

Centro e periferia na Grande Lisboa: diferenciação social e funcional, estrutura e dinamismo da zona central. Degradação do centro tradicional e desenvoivimento de novos centros.

177. RODRIGUES, MARIA JOÃo MADEIRA - «Tradição, transição e mudança. A produção do espaço urbano na Lisboa oitocentista». Boletim Cultural da Assembleia Distrital de Lisboa, Lisboa, 84, 1978, v. 3-96, bibl., il.

Desenvolvimento de Lisboa a partir do último quartel do séc. XIX. suas manifestações espaciais e causas de terminantes.

GEOGRAFIA DO TURISMO

178. Cavaco, CaRminda - Turismo e demografia no Algarve. Lisboa, Centro de Estudos Geográficos, 1979, 76 p., pol., il.

Consequências do turismo na evơnção demagráfica do Algarve (durante os últimos decénios) e movimentos dẻ população a que deu origem. o exemplo de Quarteira-Vila Moura.

179. Cavaco, Carminda - «O Turismo em Portugal. Aspector evolutivos e espaciais». Estudos Italianos em Portugal, Lisboa, 40-41-42, 1977/78/79, p. 191-280, il., bibl., gráf., quad.

O estudo sumaria o desenvolvimento das diferentes formas de turismo (termalismo, veraneio balnear, climatismo) durante os séculos xIX e Xx. Destaca depois a sua evolução nos últimos decénios, o significadio da clientela internacional, a secundarização programática do turjsmo in- terno e a afirmação do veraneio balnear, designadamente no litoral do Centro e sobretudo do Algarve.

180. Duarte, Honorato Cavaco; Amaral, Nicolad Pereira do-O alojamento turístico. Lisboa, Caixa Geral de Depósitos, 1979, 152 p., pol., quaad., gráf.

Estudo global dos problemas do sector do turismo em Portugal com particular atenção para a região do Algarve). Através da comparação de alguns indicadores, enquadramento internacional.

181. O Turismo em 1978 (Continente e llhas Adjacentes) Portugal. [Lisboa], Secretaria de Estado do Turismo, s. d., 335 p., gráf., quad.

Elementos estatísticos sobre o turismo (interno e externo), analisado por distrito, mês e rlasse de estabelecimento.

182. O Turismo na Nazaré. Coimbra, Comissão de Planeamento da Região Centro, 1979, $47 \mathrm{p}$., pol. + anexo com quadros.

Análise, por concelho, da distribuição e utilização do equipamento hoteleiro existente. Evoluçãa do afluxo tuitístico à Nazaré e sua origem

\section{GEOGRAFIA ECONÓMICA}

183. «Estimativas da situação económica». Planeamento, Lisboa, 1,1 1978, p. 125-135.

Resumo da situação económica em 1977. Quadros com o P. I. B., por ramo de actividade (de 1974 a 1977) e com os índices de produção industrial.

184. «Evoluçãa das estruturas de consumo 1958-1975». Planeamento. Lisboa, 1,1, 1978, p. 59-122, res. port. e ing.

Estudo de carácter económico em que se analisa a evolução do consumo privado (alimentar e não alimentar), através de vários indicadores (habitação, saúde, transportes, recreio, etc.).

185. Portugal. Paris, O. E.C.D. (Economic Surveys) 1979, 68 p.

Tendências recentes da economia portuguesa.

GEOGRAFIA DA INDÚSTRIA E DA ENERGIA

186. ALMEIda, Joño CARreira; Videtra, JORGE Galvão - $A$ indústria de pasta pára papel. Lisboa, Banco de Fomento Nacional, 1979, 194 p. («Estudos», 16).

Caracterização sumária da indústria. Matérias-primas, produções, mercados e perspectivas. 
187. Cantribulţção para o estudo do sector da cortiça na região do Norte (2 vols.). Porta, Comissão de Planeamento da Região do Norte, 1979 , 374 p., pol. +1 vol. de anexos, bibl., gráf., map., quad.

Depois de uma abordagem à produção suberícola a nível mundial e nacional (distribuição, produções, comercializaçño, etc.), estudo da indústria corticeira (lacalização das unidades, suas características e evolução no regiño Norte) e do seu pạel no contexto da indústria transformadora.

188. FERNANDES, JOSE - “Indústria transformadora no Continente». Boletim da Comissão de Planeamento da Região Centro, Coimbra, 6, 1978, p. 39-77 , gráf.

Com base nas "Estatísticas das Sociedades (1975), análise das características da indústria transformadora no conjunto do País. Elementos sobre tipo de sociedade, emprego, remuneração, produtividade e comercialização (a nível global e também por tipo de indústria).

189. Implantação dum parque industrial. Évora, Comissão de Planenmento da Região Sul, 1976, 43 p. pol., quad., map.

Com vista à instalação de um parque industrial em Évora, estudo das características sócio-económicas da região (população, PIB, análise económica sectorial, infra-estruturas e características das iniciativas empresariais).

190. Localização do emprego industrial. Lisboa, Centro de Estudos de Planeamento, 1979, 15 p., pol. + map. (Estudos Urbanos e Regionais, 18).

Com base no Inquérito Industrial de 1971 (e para os estabelecimentos com 20 e mais pessoas no serviço), apresentação de mapas (escala 1:500.000) com a distribuição espacial das principais indústriats (agrupadas por ramos afins) no Continente.

191. Moura, domingos; Carvalho, F; Rosa, Rui Namorado; Forte, A. F.; Caraça. Manuel G.; Redol, A. M.; Barreto, J.; Martins, J. F.; RODRIgUes, M. $-O$ que é a energia nuc.ear. Oportunidade em Portugal. Lisboa, Moraes, 1978, 277 p., il.

Série de artigos sobre as características da energia nuclear e as condições da sua inserção no contexto cultural e económico de Portugal.

192. Panoramica da indístria têxtil em Portugal. Porto, Banco Português do Atlântico, 1978, 61 p.

Depois de uma visão global do sector e do seu enquadramento no conjunto da indústria transformadora, análise dos seus subsectores (algodoeiro, lanifícios, malhas e vestuário). Anexos estatísticos.
193. ReIS, Daniel; Neves, Fernando PaUlouro-A guerra da Mina e os mineiros da Panasqueira. Lisboa, A Regra do Jogo, 1979, $141 \mathrm{p}$.

História da mina e clas lutas dos seus operários. Testemunhos.

194. SERRÃo, JOEL - "Das razões históricas dos fracassos industriais portugueses). Memórias da Academia das Ciências de Lisboa-Classe de de Letras, Lisboa, $\mathrm{xx}, 1979$, p. 7-50.

Depois de uma introdução em qụe o A. situa o contexto imperial-colonial português (do século xviI ao século xx), análise das várias crises comerciais advindas e das tentativas de industrialização subsequentes. Causas explicativas do subdesenvolvimento industrial português.

195. Sines e a indístria básica - II Encontro de Jornalistas económicos promovido pela C.N.P. - Comunicações $e$ debates. Lisbon, Publicações Europa-América, s. d., 208 p.

Resultados do debate em que foram analisadas várias questões ligadas à indústria portuguesa e os grandes planos sectoriais com implantacão em Sines (Sidenurgin, Refinaria e Petroquímica).

196. SOUSA, ALFREDO DE; BETTTENCOURT, ANTÓNIO ORTINS DE; OLIVEIRA, JAIME DA COSTA; SẼRgIo, RUI (Comissão de Redacçño) - Centrais nucleares em Portugal. Projecto de Livro Branco. Lisboa, Ministério da Indústria e Tecnologia, 1978, 619 p., quad., gráf.

Previsño sobre as necessidades de energia eléctrica em Portugal até ao ano 2000 e propostas de alternativas para a sua satisfação.

Problemas ligados à protecção do homem e do ambiente.

Avaliação económica da alternativa nuclear em paralelo com as alternativas convencionais (petróleo e carvão).

197. TeIXeIRa, José Gaspar - Da energia que temos à energia aue queremos. Confidências - Contingências-Conveniências. Lisboa, Imprensa Nacional - Casa da Moeda, 1976, $192 \mathrm{p}$.

Aspectos políticos e económicos do problema energético em Portugal.

\section{GEOGRAFIA DOS TRANSPORTES}

198. Areas de influência dos centros urbanos. Fluxos rodoviários. Transportes de passageiros, vol. II. Lisbar, Centro de Estudos de Planeamento, 1978, 155 p., pol., il., quad., map., res, port., ing. e fr. (Estudos Urbanos e Regionais, 14))

Abrange os 13 distritos a sul do Douro e completa o estudo já publicado para os do norte do Douro (ver na B. G. P. - 1976, o n. ${ }^{\circ} 179$, Finisterra, XII-24.

Inclui, além de outros parciais, um mapa (na escala 1:500 000) com as áreas de influência dos centrơs urbanos. 
199. Porto da Figueira da Foz. Coimbra, Comissão de Planeamento da Região Centro, 1979,162 p. pol.

Características físicas do porto actual, suas infra-estruturas e áren de influência. A economia do whinterland" potencial, determinada através do $\mathrm{PB}$ para 1970 e das Estatisticas do Comércio Externo (1976).

200. REIS, ALDA MARIa dOS SANTOS; ANTUNRS, ANTÓNIO JOSE PaIs; BOURA, MARIA ISABEL RAMOS; JACINTO, RUI MANUEL MISSA - "Contribuições para o estudo do impacto da auto-estrada. Lisboa-Porto na Região Centro». Boletim da Comissão de Planeamento da Regiño Centro, Coimbra 9, 1979 , p. $40-70$.

Com base na teoria dos grafos, análise da rede viária nacional e das suas componentes regionais, no intuito de prever as consequências da entrada em funcionamento da auto-estrada.

201. RODRIGUES, FÁTIMA - $O$ porto de Lisboa no pais e na cidade. Lisboa, Centro de Estudos Geográficos, 1979, 277 p., pol., quad., gráf.

Características naturais do porto, suas actividades internas e relações com o exterior. Importância económica para a cidade e para o país.

\section{PLANEAMENTO E ORDENAMENTO DO TERRITÓRIO}

202. Esłudo para a delimitação de regióes-plano, vol, I. Lisboa, Centro de Estudos de Planeamento, 19/77, 90 p., pol. (Estudos Urbanos e Regionais, 11).

Com a finalidade de fundamentar a delimitação de regióes-plano, caracterização sumária das 7 regióes propostas ( $\mathrm{sob} 0$ ponto de vista agrícola, industrial, urbano, etc.). Comparações inter-regionais de alguns indicadores.

203. Método e critérios de classificação de Municipios. Lisboa, Minjstério da Administração Interna, Direcção-Geral da Acção-Regional e Local, 1979,169 p., map., quad.

No sentido de contribuir para a reorganização do sistema administrativo (e depois de uma breve perspectiva histórica), selecção de vários indicadores para, através da utilização da análise factorial das correspondências, se determinar a natureza (urbána ou rura]) de cada município.

204. NicolaU, Fernando DA COSTA; SÁ. JoRge DE- «Tipologia socioeconómica dos municípios continentais pela análise das correspondências». Análise Social, Lisboa, Xv, 57, 1979, p. 49-67, map., res, port., fr, e ingl.

Tomando como base de observação os 274 concelhos e através da selecção de 25 variáveis de carácter económico-social, tenta-se mostrar a distribuiçño das principais estruturas económicas actuais e das diferentes classes sociais, no território.
205. SIlva, AMADo DA; SANTOS, ANíbal-Planeamento industrial e decisões de investimento (aplicação ao sector petroquimico). Lisboa, G. E. B. E. J., 1979,110 p., res. ingl.

Aplicação, ao complexo das olefinas (Sines), de técnicas de programação do investimento.

206. TUDELLA, JOSE - Planeamento territorial do espaço continental português. Subsidios para uma análise conjuntural. Lisboa, Ed. Divulgus, s. d., 94 p.

Com base em caracteristicas geográficas e demográficas do território português, apressentação de uma proposta para a sua organizaçãol regional.

\section{GEOGRAFIA REGIONAL}

207. «Almeirim. Sementes de unidade em terra fértil». Poder Local, Lisboa, 13, 1979 , p. 56464 , il.

Caracterização do concelho e suas condições de vida. Acções desenvolvidas depois do 25 de Abril de 1974.

208. Análise e diagnóstico geral da região. Distribuição das actividades trans formadoras no distrito de Castelo Branco. [Coimbra], Comissão de Planeamento da Regiño Centro, 1979, 94 p. pol., quad.

Para todos os concelhos do distrito, quadros com as unidades industriais existentes (por ramo de actividade) e com indicação da categoria e ano da instalação. Mapas com a distribuição dos vários tịos de indústria.

209. Análise e diagnóstico da siluação regional, vol. I (Geografia clima e demografia). Évora, Camissão de Planeamento da Região do Sul, 1979 102 p., pol., il.

Depois de uma caracterização sucinta da regiaño em estudo. do ponto de vista geomorfológico e climático, análise detalhada, a nível de concelho (e agrupamento de concelhos), de vários aspectos demográficos (distribuição, evolução, estrutura, mobilidade e actividades da população).

210. Basso, JosÉ MANUid - «Nisa, Adiar ou resolver os problemas?». Poder Local, Lisboa, 15,1979 , p. $58-64$.

Alguns elementos para a caracterização demográfica, económica, social e política do concelho em análise.

211. CAVACo, CARMINDA - Organizaçâo funcional do espaço numa pequena cirea limite do Algarve com o Alentejo. Lisboa, Centro de Estudos Geográficos, 1979, 31 p. pol. (Estudos de Geografia Humana e Regional C-2).

o A. pretende verificar (através das respostas a um questionário lançado em Odemira, Vila Nova de Milfontes, S. Teotónio e Odesseixe e relativo especialmente à aquisição de bens e serviços mais elementares) o significado funcional do limite administrativo dos distritos de Beja 
e Faro no sector do perímetro de rega do rio Mira. Em anexo contém o modelo de questionário utilizado.

212. Contribuição para o inventário das potencialidades turisticas da área do Douro. 2 vols. Porto, Comissão de Planeamento da Região do Norte, 1979, 130 p., pol. e 259 p., pol., map.

No $10^{\circ}$ volume é feito o levantamento do património artístico: castelos, pontes, igrejas, estações arqueológicas, etc., e no $2 .^{\circ}$ o das feiras, festas, artesanato, fontes, estâncias, museus e outros dados de jinteresse turístico.

Todos os elementos são fornecidos à escala da freguesia.

213. Desequilibrios Regionais. [Lisboa], Centro de Estudos de Planeamento, 1977, 33 p. pol., map. (Estudos Urbanos e Regionais, 13).

Através da selecção de vários indicadores, elaboração de matrizes de correlacção com a finalidade de mostrar a hierarquização do desenvolvimento. (A unidade espacial de observação é o concelho).

214. Ferreira, Finnando Airis;; Babo, AntónIo Perez - Breve caracterização do agrupamento de concelhos do Vale do Douro Superior. Porto, Comissão de Planeamento da Região do Norte, 1978, 150 p. pol., map. gráf., quad.

Depois de uma caracterização sumária da região (concelhos de Mogadouro, Torre de Moncorvo, Vila Nova de Foz Côa, Frejxo de Espada-à-Cinta e Meda), são analisados: a população e os principais sectores da actividade económica, os equipamentos existentes e os aspectos dinâmicos da acessibilidade.

215. Fidalgo, Lizette; Castro, Osvaldo - «Marinha Grande. Vencer o passado, construir o fluturo». Poder Local, Lisboa, 14, 1979, p. 47-57, il.

As origens do povoamento e a importância da indústria vidreira na sua evolução. Caracterização demográfica, económica è social do concelho.

216. JENKINS, ROBIN - The Roal to Alto-An account of peasants, capitalists and the soil in the mountains of southern Portugal. London, Pluto Press, 1979, 1157 p., quad., map.

Estudo das modificações (demográficás, agrícolas, ecológicas) introduzidas numa pequena comunidade algarvia (Alferce - S. ${ }^{a}$ de Monchique) com a construção de uma estrada.

217. LEMA, PAULa BoRdalo-Tourém. Uma aldeia raiana do Barroso. Lisboa, Centro de Estudos Geográficos, 1978, 195 p., il., bibl.

Estudo de uma pequena aldeia fronteiriça, excêntrica e isolada. Actividade agrícola, organização da sociedade, movimentos da população consequências da sua "posição" na actividade agro-pecuária e no comportamento dos habitantes.
218. Lopes, Maria Eugenta SOARES DE ALbergaria Moreira - $O$ estuário do Sado. Paisagem e dinâmica. Lisboa, Centro de Estudos Geográficos, 1979, 71 p., pol., il., bibl. (Estudos de Geognafia das Regiões Tropicais - 2)

Projecto de investigação sobre o estuário do Sado em que a $A$. se propõe analisar as inter-relações da paisagem e os factores aue determinam a dinâmica do estuário, procedendo, descle já, ao estudơ prólyio de alguns destes aspectos e apresentando abundante bibliografja.

219. "Lousñ: movimento popular prepara futuro». Poder Local, 12, 1979, p. 53-58, il.

Notas históricas, situação geográfica, principais actividades, carências e problemas da população. Também contém alguns elementos demográficos.

220. MARTinho, AlBerto - «Sabugueiro, uma aldeia da Serra da Estrela, ontem e hoje». Revista de História Económica e Social, Lisboa, 3, 1979, p. 23-52, gráf.

Aspectos demográficos, económicos e sociais.

221. MARTins, ANTónIo EPIFÂnTo CARVALHo-Pedrógão Grande: história, tradições, turismo, váric. [Coümbra, Imp. de Coimbra], 1979, 32 p. il.

Breves elementos sobre a situação, história, actividades, património artístico e cultural e potencialidades turísticas do concelho referido.

222. Oliveira, CaMILo DF-O concelha de Gondomar. Apontamentos monográficos, $4 .^{\circ}$ vol. Porto, Livraria Avisi, 1979.

Esta monografia é constituída por 4 vols, No vol. $4 .^{\circ}$ são tratados os aspectos relativos às vias de comunicacão, ao comércio, à indústria, ao equipamento e aos costumes feiras e festas do concelho.

223. Rebeito, Fernando; Quaresma, Ângela - Aveiro e sua região. Aveiro, Comissão Municipal de Turismo, 1979, 125 p., il.

Roteiro turístico com uma introdução geográfica (morfologia, clima, economia) da região.

224. A região Centro em mapas e quadros. Coimbra, Comissão de Planeamento da Região Centro, 1979, 93 p., pol.

Através de mapas e guadros, tentativa de caracterização da região dcs pontos de vistła físico, demográfico, económico e social (a maioria dos dados é fornecida apenas a nível distrital).

225. RODRIGUES, ADRIANO VASCO - Celorico da Beira e Linhares. Monografia histórica e artística. Celorico da Beina, Câmara Municipal, 1979, 247 p., il. 
Monografia que colntém, entre outros, elementos sobre a história e a vida actual do concelho, seus usos e costumes.

226. Sales, P. Esnesto Augusto Pereira DE-Mirandela. A pontamentos Históricos. Bragança, Junta Distrital de Bragança, 1978, 301 p.

Elementos sobre a história, população, actividades, economia, etc. da vila de Mirandela.

227. SAles, P. ${ }^{\circ}$ Esnesto Augusto PereIra DE-- «Sesimbra. Organizar o desenvolvimento. Poder Local, Lisboa, 11, 1979, p. 55-63, il.

Evolução da população e do povoamento. Alguns elementos sobre as actividades e os equipamentos existentes no concelho.

228. Simões, Viriato - A Serra da Estrela e as suas beiras. Lisboa, ed. do A., 1979,95 p., il., bibl.

Livro de divulgação em que são focados alguns aspectos físicos e humanos da paisagem. Mapas.

229. SOARES, JOSÉ A. DE OLIVEIRA - História da vila e concelho do Peso da Régua. Régua, Câmara Municipal, 1979, $342+$ xxxvir p.

E a $2 .^{a}$ edição de uma monografia (a $10^{a}$ é de 1936) sobre o concelho. Aspectos históricos, económicos e agrícolas (entre outros).

\section{ENSINO}

230. FerReira, CONCEIÇão COELHo; Martins, ODETE SOUSA - Iniciação à Geografia. Portugal, 8. ${ }^{\circ}$ ano de escolaridade. Lisboa, Emp. Lit. Fluminense, Lda., 1979, 320 p., il.

Manual para o ensino, com numerosa ilustração e contendo elementos sobre Portugal.

231. Gualberto, Maria HELENa; SOUSA, M. ${ }^{a}$ Lidia Figueira da-Portugal. Geografia, 8. ${ }^{\circ}$ ano unificado. Lisboa, Básica Editora,.1979, 211 p., il

Aspectos vários dą geografia de Portugal; relevo, clima, vegetação, população, espaço rural, urbano e industrial, assimetrias regionais. Inserção de Portugal no Mundo.

232. LEITÃo, M. DA LUZ - 8. ano Geografia. A Terra dos Homens. Lisboa, Plátano Editora, 1979, 235 p., il.

Um manual para o ensino secundário, contendo elementos sobre Portugal.

\section{INDICE ALFABETICO DOS AUTORES}

ABRANTES, M. L. (55)

AIRIS-BARROS, L. (83)

ALARCATO, JORGE (174)
ALMEIDA, CARLOS (137)

ALMEIDA, F. MOITINHO DE (103)

ALIMEIDA, JOÃo CARREIRA (186)
ALMEIDA, MARIA ADELAIDE S. (138)

ALPALHÃO, J. ANTÓNIO (139)

AMARAL, ILÍDIO Do (1)

AMARAL, J. L. MENDES D' (55)

AMARAL, NICOLAU PEREIRA DO (180)

AMOR'M, ANA B. (85)

ANACLETO, JOÃO JOSẼ (B3)

ANDRADE, ANTÓNIO ALBERTO BA.

NFIA DE (34)

ANDRADE, M. F. DE (55)

ÂNGELO, LIBÂNIA R. (55)

ANTUNES, ANTônio José PaIs (200)

ANTUNES, M. T. $(86,103)$

ARAÚJo, AGOSTINHO (35)

ARAúJo, IlídIo ALVES DE (36)

AZEVEDO, TERESA M. (85)

Babo, António Perez (214)

Balabanian, OLIVIER (156)

BARBOSA, JORGE (121)

BARRETO, J. (191)

BARROS, AFONSO DE $(157,158)$

BASSO, JOSE MANUEL (210)

Baumfeld, Carlos Minc (159)

BENIS, MARIA IOANNIS (37)

BERTHOU, P. Y, (87)

BETTENCOURT, ANTÓNIO ORTINS DE

(19)

BETTENCOURT, MANUEL L. (71)

BIROT, P. (74, 75)

BOILLOT, G. (88)

BOURA, ISABEL (140)

BOURA, MARIA ISABDL RAMOS (200)

CABRAL, ANTÓNIO (122)

CABral, MANuel Villaverde (38)

CaraÇa, Manuel G. (191)

CARDOSO, JOÃO L. $(58,85)$

CARDoso, M. D DE F. M. (55)

CARDOSO, MÁRIO (123)

CARNEIRO, ANA PAULA (109)

CARREIRA, ANTónIo (39)

CARRILHO, MARIA JOSÉ (1141)

Carvalio, agostinho de (160)

Carvalho, D. DE (103)

CARVALHo, F, (191)

Carvalhosa, A. barros e $(9,12)$

Caste-o-Branco, Fernando (40)

CASTRO, OSVALDO (215)
CAVACO, CARMINDA $(142,161,162$, $178,179,2 i 11)$

COELHO, VIRGINIA (41)

CONSTÂNCIO, SOLANO (22)

Cordovil, Francisco Cabral (163)

CORREIA, ALberto $(124,125,126)$

COSTA, MANUEL FERNANDES (68)

COSTA, M. GONÇALVES DA (43)

COUDÉ-GAUSSEN, GENEVIÈVI (76)

DAVEAU, SUZANNE $(75,77)$

DRAIN, M. (164)

Duarte, honorato Cavaco (180)

DUPEUBLE, P. A. (95)

FARIA, J. M. DA ROCHA (72)

FERNANDEIS, ANTÓNIO LUÍS (110)

FERNANDES, JOSÉ (188)

FERRÃo, JOÃo MANUtel MACHAdO (143)

FERREIRA, ANTÓNĨo DE BRUM (75, 78)

FERREIRA, CONCEIÇÃO COELHO (230)

FERREIRA, FERNANDO AIRES (214)

FERREIRA, M. P. (103)

FERREIRA, O. DA VEIGA $(11,12)$

FERRO, MARIA JOSE PIMENTA (44)

FIDAIGO, LIZETTE (215)

FIGUEIRAS, JORGE (85)

FONSECA, ISABEL (144)

FONTES, ANTÓNIO LOURENÇO (127)

FORTE, A. F. (191)

FREUND, BODO (115)

Galletti, Regine Crosaz (90)

GASPAR, JORGE $(116,175,176)$

GERALDES, ALICE (128)

GODARD, ALAIN (75)

GODINHO, SILVERIO FIGUEIREDO (69)

GONÇALVES, FRANCISCO (9)

GONÇALVES, IRIA (45)

GONÇALVES, JOÃO LUDGERO MAR-

QUES, 61, 62)

GONÇALVES, VICTOR DOS SANTOS (60)

GRANCHO, MARIA AUGUSTA (110)

GRELOU-ORSIN, CAMMILLE (75)

GUALBERTO, MARIA HELENA (231)

GUIFRREIRO, M. VIEGAS (129)

GUICIFIARD, FranCOIS (145) 
GUILLEMOT, E. (79)

HENRIQUES, RENANO (165)

HENRIQUES, TITO (165)

JACINTO, RUI (140)

JACINTO, RUI MANUEL MISSA (200)

JENTINS, ROBIN (216)

JONET, S. (91)

JÚDICE, EUGÉNIO (111)

LAGES, MÁRIO (146)

LAUVERJAT, J. (37)

LEITÃO, MARIA DA LUZ (232)

LEITE, MARIA C. (55)

LEMA, PAULA BORDALO (217)

LOBO, ANTONIO DE SOUSA SILVA Costa (46)

LOPES, ANA MARIA SIMÕES DA SILVA

(130)

MACHADO, M. J. SOUSA (72)

MAIA, CLARINDA DE AZIVEDO (131)

MALOD, J. A. $(88,95)$

MANUPPELLA, GIUSEPPE $(92, \quad 93$,

94).

MARQUES, B. (104)

MARQUES, M. MONTEIRO (80)

MARTINHO, ALBERTO (220)

MARTINS, ANTóNIO EPITÂNIO CAR.

VALFIO (221)

MARTiNS, J. Ávila (10)

MARTINS, J. F. (191)

MARTINS, ODETE SOUSA (230)

MEDEIROS, CARLOS ALBERTO (142)

MENDES, FERNANDO RIBEIRO (158)

MEINDES, Guilherme (158)

MONICA, MARIA FILOMENA, (53)

MONIZ, FERNANDO (153)

MONTEIRO, J. H. $(95,103)$

MOREIRA, J. C. BALACó (92, 93, 94)

Moreira-Lopes, Maria Eugénia $S$. de A. (21'8)

MORGado, Nuno ALVES (148)

Mougenot, D. $(81,88,95)$

MOUNIER, J, (70)

MOURA, DOMINGOS (19:1)

MOUTERDE, R. (96, 97)

MOUTINHO, MARIO C. (120)

NASCIMENTO, JOÃO (150)
NAZARETH, J. MANUEL (151)

NEVES, C. M. L. BAETA (112)

Neves, FERnando paulouro (193)

NICOLAU, FERNANDO DA COSTA (204)

NUnes, Maria ARMinda ZaLUar

(136)

Oltveira, AURÉlio de ARAÚJo (47)

OLIVEIRA, CAMILO DE (222)

OLIVEIRA, JAIME DA COSTA (196)

Oliveira, J. M. SANTOS (101)

PAIS, J. (98)

PaIXÃo, Carlos Albuquerque (167)

PaLAIN, C. (99)

PALIMINHA, Luís (168)

Penalva, C. $(58,63,64)$

PERDIGÃo, JACINTO CORREIA (100)

PPEREIRa, ANa Ramos (60)

PEREIRA, ESTEVES (48)

PEREIRA, MÃRIo (169)

PEREIRA, Miriam HALPERN (49)

Pinhetro, Magda DE AVelar (50)

PINTO, ANTónIo Nunes (51)

PIRES, C. BORGES (170)

POLANAH, LUIS (132)

PORTO, MANUEL CARLOS LOPES (152)

QUARESMA, ÂNGELA (223)

QUARESMA, JOSÉ ALBERTO (33)

RAMOS, J. M. FARINHA (101)

RAMOS, LUIS ANTÓNIO DE OLIVEIRA

(52)

RAYNAL, RÉNÉ (82)

REBELO, FERNANDO (223)

REDOL, A. M. (191)

REIS, ALDA MARIA DOS SANTOS (200)

REIS, DANIEL (193)

REIS, JAIME $(53,54)$

ReIS, Maria Alice (117)

REY, J, (102)

RIBEIRO, A. (103)

RIBLIRO, JOSÉ ANTÓNIO PINTO (133)

RIBEIRO, JOSÉ JÚLIO (160)

RIBEIRO, MARIA LUÍSA (10)

RIBEIRO, ORLANDO $(75,118,119)$

ROCHA, EDGAR (172)

ROCHA, R. B. (96, 97, 103, 104)

RODRIGUES, ADRIANO VASCO (225)
RODRIGUES, CRISTINA M. G. (55)

RODRIGUES, FATIMA (201)

RODRIGUES, M. (191)

RODRIGUES, MARIA JOÃO MADEIRA (177)

ROSA, RUI NAMORADO (191)

ROSA, VICTOR M. P. DA (139)

ROSEIRA, MARIA JOÃo QUEIROZ (4)

Ruget, CH. (96, 97)

$\mathrm{SA}$, JORGE DE (204)

SAles, P. ERnesto Augusto PEREIRA DE (226)

SANTA-RITTA, GONÇALO (173)

SANTOS, ANIBAL (205)

SANTOS, ARLETTE DOMINGOS DOS (11)

SANTOS, CÂNDIDO DOS (56)

Santos, Maria DE Lourdes lima DOS (5)

SERGIO, RUI (196)

SERRA, PEDRO CUNHA (134)

SERRÃO, EDUARDO DA CUNHA (65)

SERRÃO, JOEL (194)

SILVA, AMADO DA (205)

Silva, Carlos Tavares da (66)

SILVA, J. HENRIQUES DA (153)

SILVEIRA, ADRIANO (113)
ILVEIRA, MARIA ISABEL PORTUGaL DA (110)

SIMÕES, VIRIATO (228)

SOARES, A. F. (103)

SOARES, JOAQUINA (66)

SOARES, JOSE A. DE OLIVEIRA (229)

SOARES, MARIA MICAELA (135)

SOUSA, ALFREDO DE (196)

SOUSA, Fernando ALberto PEREIRA

$\mathrm{DE}(57)$

SOUSA, JOÃo S. DE (55)

SOUSA, MARIA EDUARDA T. DE (110)

SOUSA, MARIA LIDIA FIGUEIRA DE

(231))

SoUsa, Mário da SILVA (114)

TAPADAS, M. ${ }^{\circ}$ A. (55)

TAVARES, ANT6NIO AUgusto (67)

T'EIXEIRA, CARLOS (105, 106, 107)

TEIXEIRA, JosÉ Gaspar (197)

TINTANT, H. (96)

TRINDADE, MARIA BEATRIZ ROCHA (154)

TUDELLA, JOSÊ (206)

WILSON, R. C. L. (108)

WISNIEWSKI, J. (155)

VANNEY, J. R. (81)

VASconceldos, J. LeitTE DE (136)

VIDEIRA, JORGE GALVÃO (186)

ZBYSZEWSKI, G. (19, 11, 12, 103)

\section{ABREVIATURAS UTILIZADAS}

a. - autor

art. ${ }^{\circ}$ - artigo

bibl. - bibliografia

B. G. P. - Bibliografia Geográfica

de Portugal

col,- colecção

colab. - colaboradores

ed. - edição

esp. - espanhol

fr. - francês

gráf. - gráfico -

il. - ilustrado

$$
\begin{aligned}
& \text { ing. - inglês } \\
& \text { map. - mapas } \\
& \text { n. } .^{\circ} \text { - número } \\
& \text { p.- página } \\
& \text { pol. - policopiado } \\
& \text { port. - português } \\
& \text { quad. - quadro } \\
& \text { res. - resumo } \\
& \text { sep. -- separata } \\
& \text { s. } 1 . \text { - sem lugar } \\
& \text { s. d. - sem data } \\
& \text { vol. - volume }
\end{aligned}
$$

MARIA JOÃO QUEIROZ ROSEIRA 